\title{
Rivaroxaban Induced Protein S Deficiency
}

Y Bhusal $^{1}$, S Dahal ${ }^{1}$, L Upadhyay $^{1}$, BK Shah ${ }^{2}$

\section{Affiliations: \\ ${ }^{1}$ St. Joseph Regional Medical Center, Lewiston ID USA \\ ${ }^{2}$ North Puget Cancer Center, Sedro-Woolley, WA USA}

\section{Correspondence:}

Dr B Shah

2000 Hospital Drive

Sedro-Woolley WA

USA 98284

E-mail: binay.shah@gmail.com

Keywords: Protein S, Protein Xa, Rivaroxaban 
The Editor,

Sir,

Protein $\mathrm{S}$ is a vitamin $\mathrm{K}$ dependent plasma glycoprotein with anticoagulant properties (1). It acts as a cofactor for activated protein $\mathrm{C}$ and tissue factor pathway inhibitor (TFPI). TFPI tightly binds to factor Xa and slowly inhibits it (2). Protein S deficiency can be hereditary, or acquired due to vitamin $\mathrm{K}$ deficiency, chronic liver disease, nephrotic syndrome, malignancy, systemic lupus erythematosus, disseminated intravascular coagulation, pregnancy, estrogen use as well as recent surgery and thrombosis (3-6). Warfarin decreases protein S activity by inhibiting its vitamin K dependent synthesis in liver (3). In this article, we report a patient with deep vein thrombosis who developed protein $\mathrm{S}$ deficiency on rivaroxaban therapy.

A 33-year-old male presented to the hematology clinic for the evaluation of a hypercoagulable state. The patient had been taking rivaroxaban for over a year after he was diagnosed with deep venous thromboses in the right brachiocephalic, subclavian and cephalic vein by doppler ultrasonography. At the time of diagnosis of deep venous thrombosis, the patient was receiving total parenteral nutrition and antibiotics for gastroparesis and bacteremia through an intravenous line in his right upper extremity. He had no family history of blood dyscrasias or primary hypercoagulable states. On examination, his vitals were normal. Systemic examination was negative for lymphadenopathy or hepatosplenomegaly. Laboratory investigations showed normal blood counts. His liver function and kidney function were normal. Hypercoagulability workup was negative for antiphospholipid antibodies, factor V mutation and G20210A mutation in the prothrombin gene. Further studies showed normal antithrombin 3 and protein $\mathrm{C}$ activity. 
However, protein S activity was 63\% (reference range: $70-150 \%$ normal). Repeat protein S activity after two months was still low at $63 \%$. The patient's anticoagulation therapy was changed from rivaroxaban to low molecular weight heparin (enoxaparin). After two weeks of switching the medication, his protein S activity increased to $75 \%$.

Rivaroxaban is a selective, competitive and direct inhibitor of factor Xa (7). It is an oral anticoagulant used for the treatment and prophylaxis of deep vein thrombosis and pulmonary embolism and for prevention of stroke and systemic embolism due to nonvalvular atrial fibrillation $(8,9)$. To the best of our knowledge, this is the first reported case of rivaroxaban induced protein $\mathrm{S}$ deficiency as suggested by the temporal association between rivaroxaban and reduction in protein $\mathrm{S}$ activity. The exact mechanism is not clear. During hypercoagulable workup, it may be important to switch rivaroxaban to unfractionated heparin or low molecular weight heparin prior to estimating protein $\mathrm{S}$ activity. 


\section{REFERENCES}

1. García de Frutos P, Fuentes-Prior P, Hurtado B, Sala N. Molecular basis of protein S deficiency. Thromb Haemost 2007; 98: 543-56.

2. Comp PC, Nixon RR, Cooper MR, Esmon CT. Familial Protein S Deficiency is Associated with Recurrent Thrombosis. J Clin Invest 1984; 74: 2082-8.

3. Lipe B, Ornstein D. Deficiencies of Natural Anticoagulants, Protein C, Protein S, and Antithrombin. Circulation. 2011; 124(14): e365-e368.

4. D'Angelo A, Vigano-D'Angelo S, Esmon C, Comp P. Acquired deficiencies of protein S. Protein $\mathrm{S}$ activity during oral anticoagulation, in liver disease, and in disseminated intravascular coagulation. J Clin Invest 1988; 81(5): 1445-1454.

5. Van Ommen C, Fijnvandraat K, Vulsma T, Delemarre-van de Waal H, Peters M. Acquired protein S deficiency caused by estrogen treatment of tall stature. J Pediatr 1999;135(4):477481.

6. Song K, Park Y, Kim H. Prevalence of anti-protein S antibodies in patients with systemic lupus erythematosus. Arthritis Rheum 2000; 43(3): 557.

7. Samama M. The mechanism of action of rivaroxaban - an oral, direct Factor Xa inhibitor - compared with other anticoagulants. Thromb Res 2011; 127(6): 497-504.

8. Mueck W, Schwers S, Stampfuss J. Rivaroxaban and other novel oral anticoagulants: pharmacokinetics in healthy subjects, specific patient populations and relevance of coagulation monitoring. Thromb J 2013; 11(1): 10.

9. Thomas T, Ganetsky V, Spinler S. Rivaroxaban: An Oral Factor Xa Inhibitor. Clin Ther 2013; 35(1): 4-27 